\title{
CARACTERIZAÇÃO TECNOLÓGICA DA MADEIRA DE TRÊS ESPÉCIES FLORESTAIS CULTIVADAS NO AMAZONAS: ALTERNATIVA PARA PRODUÇÃO DE LENHA
}

\author{
Sâmia Valéria dos Santos Barros ${ }^{1}$, Claudete Catanhede do Nascimento ${ }^{2}$, Celso Paulo de Azevedo \\ ${ }^{1}$ Tecnóloga da Madeira, Doutoranda em Engenharia Florestal, UFPR, Curitiba, PR, Brasil - samia_vsb@hotmail.com \\ ${ }^{2}$ Tecnológa da Madeira, Dr ${ }^{\mathrm{a}}$, INPA, Manaus, AM, Brasil - catanhed@ inpa.gov.br \\ ${ }^{3}$ Eng. Florestal, Dr., Embrapa Amazônia Ocidental, Manaus AM, Brasil - celso.azevedo@cpaa.embrapa.br
}

Recebido para publicação: 10/11/2011 - Aceito para publicação: 08/11/2012

\begin{abstract}
Resumo
As espécies florestais Acacia mangium, Inga edulis e Tachigalia chrysophyllum foram pré-selecionadas para utilização em plantios energéticos. Com o objetivo de caracterizar essas espécies, foram realizados testes a partir das variáveis densidade básica, poder calorífico e análise imediata. O experimento foi implantado na Estação Experimental da EMBRAPA no município de Iranduba/AM. O delineamento foi em blocos ao acaso com três repetições, perfazendo 9 parcelas compostas de 25 plantas cada. Foram retiradas cinco árvores dentre as nove centrais da área útil. Destas, foram retirados os discos com $5 \mathrm{~cm}$ de espessura e desdobrados em corpos de prova, para se determinar a densidade básica e demais testes. Realizou-se análise de variância e teste de Tukey a 5\% de probabilidade. A Acacia mangium $(24,16 \mathrm{~cm}$ - 13,09 m) superou as demais em diâmetro e altura, respectivamente. Os dados médios obtidos para densidade básica classificam todas as espécies como madeira de densidade baixa, média e levemente densa. O poder calorífico observado em Acacia mangium $(4430,37 \mathrm{kcal} / \mathrm{kg}$ ) foi estatisticamente superior às demais espécies. $\mathrm{Na}$ análise imediata, as espécies apresentaram resultados satisfatórios, sendo apontadas como madeiras adequadas para uso no processo da queima. Os resultados demonstram que as espécies possuem qualidade para produção de lenha.
\end{abstract}

Palavras-chave: Biomassa; densidade básica; poder calorífico; análise imediata; plantio.

\begin{abstract}
Energetic characterization of native and exotic forest species cultivated at Amazonas. The forest species Acacia mangium, Inga edulis and Tachigalia chrysophyllum were pre-selected to be used at energetic crops. In order to their characterization, tests of basic density, heating power and immediate analysis were performed. The experiment was carried out at EMBRAPA's Experimental Station, located at Iranduba/AM and was designed as randomized blocks, with three repetitions, comprising 9 plots with 25 plants each. Five trees were removed from the nine central ones of the utile area. Discs of $5 \mathrm{~cm}$ thick were removed from them and divided into proof bodies to evaluate basic density and other variables. Analysis of variance and Tukey test at $5 \%$ of probability were done. Acacia mangium $(20.82 \mathrm{~cm}-13.41$ $\mathrm{m})$ presented greater diameter and height, respectively, than the other species. The data of basic density average classified all three species as low, medium and dense-lightly density wood. The heating power observed for Acacia mangium (4430.37 kcal/ $\mathrm{kg}$ ) was statistically superior to other species. All three species presented satisfactory results at immediate analysis, being identified as suitable woods for use in burning process. Results show that the species present quality for fire wood production.

Keywords: Biomass; basic density; heating power; immediate analysis; planting.
\end{abstract}

\section{INTRODUÇÃO}

Estudos mostram que a combustão direta da madeira é, sem dúvida, o processo mais simples e econômico de obter energia (QUIRINO et al., 2004). Além disso, o uso da madeira tem outro aspecto ambiental favorável, já que a emissão de $\mathrm{CO}_{2}$ da queima da biomassa na atmosfera geralmente é compensada pela absorção no plantio da nova biomassa (INGHAM, 1999).

Dessa forma, essas vantagens tornam interessante o uso da madeira para fins energéticos, necessitando, no entanto, de uma caracterização adequada. Segundo Vale et al. (2000), a utilização de 
uma determinada madeira para fins energéticos deve basear-se, entre outros aspectos, no conhecimento do seu poder calorífico e no seu potencial para produção de biomassa.

Junge (1975), Arola (1976) e Corder (1976) indicaram o poder calorífico, o teor de umidade, a densidade e a análise imediata como as propriedades mais importantes da madeira para sua utilização como combustível.

O poder calorífico é um parâmetro que mede a eficiência energética e serve como importante indicador para se conhecer a capacidade calorífica de uma determinada espécie (OLIVEIRA, 1982).

A análise imediata é um teste que fornece a percentagem de umidade, material volátil, carbono fixo e cinzas, ou seja, ela fornece a percentagem do material que se queima no estado gasoso (material volátil) e no estado sólido (carbono fixo), bem como dá uma indicação do material residual (cinzas). Arola (1976) afirma que, quando a lenha é queimada, geralmente 75 a $80 \%$ são materiais voláteis, 20 a $24 \%$ são carbono fixo e 1 a $3 \%$, cinzas. O teor de umidade é um fator que influencia o valor do poder calorífico: quanto menor, maior será a produção de calor por unidade de massa.

Outro parâmetro para avaliação da qualidade da madeira é representado pela densidade básica, que está ligada diretamente com as propriedades físicas, mecânicas e anatômicas, podendo assim caracterizar o uso final da madeira (REZENDE et al., 1998).

De acordo com Schumacher (2003), no Brasil a implantação de maciços florestais, na grande maioria formados por espécies exóticas, são consequência da evolução de toda uma estrutura industrial. Esta tem como objetivo atender a demanda das regiões mais desenvolvidas do país com matéria-prima necessária para a produção de papel, celulose, chapas, aglomerados, carvão vegetal, móveis e outros.

O setor residencial é um importante consumidor de lenha para geração de energia no Brasil. Nesse setor, a madeira é fortemente usada para cocção de alimentos e, em menor escala, para aquecimento domiciliar. Destacam-se outros setores, o industrial e o comercial, que também a utilizam como fonte de energia para uso no ramo do cimento químico, papel e celulose e cerâmica, além do setor agrícola, para secagem de grãos (BRITO, 2010).

No município de Iranduba, no estado do Amazonas, há um grande consumo de lenha por duas partes distintas. A primeira refere-se às pequenas comunidades dessa região, cujas famílias sobrevivem dessa matéria-prima. Porém essas comunidades enfrentam problemas, como a busca da matéria-prima, que se torna cada vez mais escassa, devido à extração predatória e falta de reposição da cobertura florestal, pois, à medida que esta vai se esgotando, mais longe ficam as florestas para coleta da madeira.

A segunda parte é composta pelas olarias. A existência delas se deve à grande concentração de argila ocorrente no solo da região, favorecendo a produção de tijolos e telhas.

Visando amenizar os impactos causados, a Empresa Brasileira de Pesquisa e Agropecuária (EMBRAPA) vem desenvolvendo, por meio do experimento "Seleção de espécies florestais nativas e exóticas com potencial para produção de energia na região de Iranduba/AM", um estudo que objetiva a implementação de plantios que possam atender a necessidade do consumo de lenha das populações tradicionais do município de Iranduba, que possa ser usufruído por um período de médio a curto prazo.

As espécies utilizadas pertencem à família Fabaceae. A Acacia mangium Willd pertence à subfamília Mimosaceae. Trata-se de uma leguminosa arbórea nativa do nordeste da Austrália, Papua Nova Guiné e leste da Indonésia (Ilhas Molucas e Java). A segunda espécie é a Inga edulis Mart, subfamília Mimosaceae, nativa do Brasil amazônico, Bolívia, Peru, Equador e Colômbia. Essa espécie foi também introduzida na maior parte da América do Sul tropical, Panamá e Costa Rica. A terceira espécie é Tachigali chrysophylla (Poepp.) Zaruchi \& Herend, da subfamília Caesalpiniaceae. Essa espécie ocorre em todos os estados da Amazônia brasileira, no Peru e na Venezuela. Habita a floresta alta da terra firme, sendo conhecida popularmente como taxi-vermelho.

Nesse contexto, o presente trabalho teve como objetivo caracterizar tecnologicamente a madeira das espécies florestais Acacia mangium, Inga edulis e Tachigali chrysophylla, como indicação de possíveis espécies produtoras de biomassa, para atender as comunidades tradicionais do município de Iranduba/AM no consumo de lenha.

\section{MATERIAL E MÉTODOS}

\section{Localização e descrição do experimento em campo}

Os trabalhos de campo foram conduzidos na "Estação Experimental do Caldeirão", de propriedade da EMBRAPA Amazônia Ocidental, localizada no município de Iranduba, no estado do Amazonas, abrangendo uma área absoluta de $2.354 \mathrm{~km}^{2}$. 
O município está compreendido entre as latitudes $3^{\circ} 00^{\prime}$ e $4^{\circ} 00^{\prime} \mathrm{S}$ e longitude $60^{\circ} 00^{\prime}$ e $61^{\circ} 00^{\prime} \mathrm{W}$ Grw, situando-se no Médio Amazonas. É constituído em grande parte de terrenos quartenários recentes, cujos solos são colmatados anualmente pelas enchentes dos grandes rios (BRASIL, 1979).

O clima da área é do tipo Afi, pertencente ao grupo de clima tropical chuvoso, de acordo com a classificação climatológica de Köppen (RIBEIRO, 1976).

O experimento foi implantado em janeiro de 1995, quando foram testadas as espécies (tratamentos) em delineamento em blocos ao acaso, com três repetições, perfazendo 9 parcelas compostas de 25 plantas cada, no espaçamento de 4 x $4 \mathrm{~m}$. Os blocos I e II foram instalados em terrenos degradados, compactados, anteriormente utilizados com culturas de ciclo curto. O bloco III foi instalado imediatamente após o corte de uma área de floresta secundária de aproximadamente 20 anos.

\section{Amostragem e coleta de dados}

Durante o período do experimento, foram realizadas as medições dos elementos dendrométricos (altura e diâmetro/DAP), executadas com o auxílio de uma vara métrica e uma fita diamétrica, respectivamente, para acompanhar o desenvolvimento das espécies em todas as árvores das parcelas.

Em 2002 foi realizada a derrubada das árvores, para retirada de amostras para os testes experimentais. De cada parcela, eliminou-se a bordadura e selecionaram-se da área útil, aleatoriamente, cinco árvores dentre as nove centrais. Após a derrubada, as árvores selecionadas foram marcadas e delas retirados discos com $5 \mathrm{~cm}$ de espessura, localizados em diferentes alturas do fuste (base, DAP, 25\%, 50\%, $75 \%$ e 100\%), tendo como parâmetro o diâmetro mínimo de $5 \mathrm{~cm}$ na ponta mais fina. Posteriormente, os discos foram desdobrados e confeccionadas as amostras (corpos de prova) para o teste de densidade básica.

\section{Descrição dos experimentos em laboratório \\ Densidade básica}

A densidade básica das espécies foi determinada pelo método de imersão, segundo Vital (1984) e norma da Associação Brasileira de Normas Técnicas (ABNT) NBR 11941/03, na Coordenação de Pesquisa de Produtos Florestais do Instituto Nacional de Pesquisas da Amazônia (INPA). As amostras foram submersas em água até que atingissem peso constante (saturação). Posteriormente, a partir de um Becker com água, mediu-se o volume das amostras pelo método de deslocamento por imersão. O peso seco foi obtido após o acondicionamento das amostras na estufa com circulação de ar, com temperatura de $103^{\circ} \mathrm{C}$, até atingirem peso constante.

Posteriormente à determinação da densidade básica, as amostras secas foram utilizadas para determinação do poder calorífico e análise imediata.

\section{Poder calorífico}

Após o preparo das amostras (picagem, moagem e classificação em peneiras, utilizando fração abaixo de 60 mesh), foi determinado o poder calorífico superior (PCS), utilizando-se um calorímetro PARR modelo 1341, segundo a norma ABNT NBR 8633/84 e manual de operações do calorímetro. Os testes de calorimetria foram realizados no Laboratório de Caracterização Físico-Química de Biomassas, do Centro de Desenvolvimento Energético Amazônico (CDEAM), na Fazenda Experimental da Universidade Federal do Amazonas, localizada na BR 174, km 38.

Nesse procedimento, a amostra de aproximadamente $1,0 \mathrm{~g}$ a ser analisada é pesada num cadinho e colocada no reator do calorímetro, chamada bomba calorimétrica. Esta é carregada com $5 \mathrm{ml}$ de água e pressurizada com oxigênio a uma pressão de $3,0 \mathrm{Mpa}$. A bomba foi ativada com temperatura variando de 26,82 a $30,54^{\circ} \mathrm{C}$, sendo acompanhada constantemente por meio de termômetro a ela acoplado. Esse procedimento foi realizado em duplicata para cada espécie.

Análise imediata

A análise imediata consiste na determinação do teor de umidade (TU), material volátil (MV), cinzas (CZ) e carbono fixo (CF), segundo a norma ABNT NBR 8112/86.

Para determinação da análise imediata, utilizaram-se amostras secas, picadas, moídas e classificadas em peneiras, sendo utilizada a fração entre 40 e 60 mesh. Os testes foram realizados em duplicatas para cada espécie, de acordo com a norma, no Laboratório de Análises Físico-Químicas (LAFQ) do Centro de Desenvolvimento Energético Amazônico (CDEAM) da Universidade Federal do Amazonas. 


\section{Análise dos dados}

A análise estatística para estimativa das diferenças entre médias foi realizada com auxílio do programa SAS (Statistical Analysis Sistems), considerando a significância mínima de 5\% de probabilidade pelo teste de Tukey.

\section{RESULTADOS E DISCUSSÃO}

\section{Características dendrométricas}

Na tabela 1 são observados os valores médios e desvio padrão das variáveis dendrométricas para as espécies mensuradas durante o período do experimento, verificando-se, ainda, se as espécies cultivadas apresentaram adaptabilidade ao local e rápido crescimento.

Tabela 1. Valores médios e desvio padrão das características dendrométricas.

Table 1. Average values and standard deviation of dendrometric characteristics.

\begin{tabular}{lllll}
\hline \multirow{2}{*}{ Espécie } & \multicolumn{2}{c}{ DAP $(\mathbf{c m})$} & \multicolumn{2}{c}{ Altura $(\mathbf{m})$} \\
\cline { 2 - 5 } & Média & DP & Média & DP \\
\hline Acacia mangium & $24,16 \mathrm{a}$ & 6,85 & $13,09 \mathrm{a}$ & 2,25 \\
Tachigali chrysophylla & $9,75 \mathrm{~b}$ & 3,67 & $8,55 \mathrm{~b}$ & 2,95 \\
Inga edulis & $6,74 \mathrm{c}$ & 2,79 & $4,57 \mathrm{c}$ & 1,35 \\
\hline
\end{tabular}

Médias seguidas pela mesma letra, dentro da mesma coluna, não diferem estatisticamente ao nível de $5 \%$ de probabilidade pelo teste de Tukey.

Observou-se que há diferença significativa nas médias das características dendrométricas das três espécies estudadas. Entretanto, os valores de desvio padrão apresentados revelam que houve baixa variabilidade dos dados entre as árvores para cada espécie.

A espécie Acacia mangium destacou-se em diâmetro $(24,16 \mathrm{~cm})$ e altura $(13,09 \mathrm{~m})$, enquanto as espécies Tachigali chrysophylla e Inga edulis apresentaram dados estatísticos inferiores. Entre as três espécies, a Acacia mangium é a melhor em produção de biomassa.

Verifica-se que, mesmo com diferença significativa, as espécies apresentaram diâmetro satisfatório para uso na forma de lenha, pois, de acordo com estudo realizado por Couto et al. (1989) sobre mensuração e gerenciamento de pequenas florestas, considera-se o diâmetro mínimo para lenha de $3 \mathrm{~cm}$. Baggio et al. (1995), estudando a bracatinga (Mimosa scabrella Benth), observaram que o diâmetro mínimo para lenha decresceu de 6,0 para até $3,0 \mathrm{~cm}$.

$\mathrm{O}$ espaçamento adotado foi um fator que contribuiu para o desenvolvimento das espécies. Com dimensão 4 × 4 m, a competição entre as árvores das parcelas foi minorada, resultando menor porcentagem de dominadas e uniformidade do povoamento, além de maior incremento da biomassa. Essa característica também foi observada por Brasil e Ferreira (1971), quando afirmam que o espaçamento tem influência marcante na produção e qualidade da madeira, principalmente no manejo de povoamentos cujo objetivo é a produção de madeira industrial de rápido crescimento e densidade adequada.

Trugilho et al. (2001) afirmam que as características de crescimento (DAP, altura, volume e biomassa) precisam ser estudadas simultaneamente à avaliação da qualidade energética da madeira.

\section{Densidade básica}

Na tabela 2 são observados os valores médios, desvio padrão, mínimo e máximo da variabilidade da densidade entre as espécies.

Tabela 2 Valores médios e desvio padrão da densidade básica das espécies.

Table 2. Average values and standard deviation of basic density of species.

\begin{tabular}{lcccc}
\hline \multirow{2}{*}{ Espécie } & \multicolumn{3}{c}{ Densidade básica $\left(\mathbf{g} / \mathbf{c m}^{3}\right)$} & Máximo \\
\hline Acacia mangium & Média & DP & Mínimo & 0,66 \\
Inga edulis & $0,58 \mathrm{a}$ & 0,06 & 0,46 & 0,63 \\
Tachigali chrysophylla & $0,52 \mathrm{ab}$ & 0,06 & 0,44 & 0,54 \\
\hline
\end{tabular}

Médias seguidas pela mesma letra, dentro da mesma coluna, não diferem estatisticamente ao nível de 5\% de probabilidade pelo teste de Tukey. 
A análise de variância indicou que as médias da densidade básica entre as espécies apresentaram diferenças significativas. A espécie Acacia mangium $\left(0,58 \mathrm{~g} / \mathrm{cm}^{3}\right)$ apresentou maior média da densidade básica, seguida de Inga edulis $\left(0,52 \mathrm{~g} / \mathrm{cm}^{3}\right)$. Entretanto, os desvios-padrão apresentados inferem que a variação da densidade básica entre as árvores nas espécies, de forma geral, é bem homogênea.

O valor de densidade básica encontrado para essas espécies é próximo do valor encontrado por Araújo (2000), quando estudou a introdução da espécie exótica Azadirachta indica A. Juss $\left(0,57 \mathrm{~g} / \mathrm{cm}^{3}\right)$ na região semiárida do Nordeste, e também semelhante a resultados de Lima (1984) com a espécie exótica Leucaena leucocephala Wit. $\left(0,54 \mathrm{~g} / \mathrm{cm}^{3}\right)$ em região semiárida.

Foi verificada, ainda, uma amplitude nos dados de densidade básica entre as espécies, sendo observada nos valores mínimos e máximos a variabilidade da densidade dentro e entre as espécies analisadas. O valor mínimo observado foi de $0,39 \mathrm{~g} / \mathrm{cm}^{3}$ para a espécie Tachigali chrysophylla, enquanto o maior valor foi $0,66 \mathrm{~g} / \mathrm{cm}^{3}$ para Acacia mangium. Essa relação de mínimo e máximo contribui para definir padrões de densidade básica dentro e entre as espécies. A partir dos dados obtidos, as espécies analisadas podem ser classificadas como madeiras de densidade baixa, média e moderadamente pesada.

Nesse contexto, Vale (2002), estudando a densidade básica da madeira das espécies do cerrado, encontrou uma variação de $0,20 \mathrm{~g} / \mathrm{cm}^{3}$ a $0,78 \mathrm{~g} / \mathrm{cm}^{3}$. O uso de madeiras com baixa densidade para a produção direta de energia na forma de calor implica uma queima rápida e uma menor produção de energia por unidade de volume, ao contrário de madeiras com maiores densidades. Porém, densidade muita elevada implica dificuldade de iniciar a queima do material. Para a queima direta na cocção de alimentos, sugere-se a faixa intermediária entre madeiras médias e madeiras duras, variando a densidade básica e esperando, com isso, facilitar o início da queima.

Avaliando clones de Eucalyptus grandis Hill ex Maiden e clones de Eucalyptus saligna Sm. aos sete anos de idade, Trugilho et al. (2001) observaram que a densidade básica da madeira está correlacionada com os teores de carbono fixo, materiais voláteis e quantidade de cinzas.

\section{Poder calorífico e análise imediata}

Observam-se na tabela 3 os valores médios para o poder calorífico superiores (PCS) e análise imediata das espécies.

Tabela 3. Valores médios de poder calorífico e análise imediata.

Table 3. Average values of heating power and immediate analysis.

\begin{tabular}{lccccc}
\hline Espécie & PCS $\mathbf{( K c a l / k g )}$ & Umidade & Material volátil & Cinzas & Carbono fixo \\
\hline Acacia mangium & 4430,37 & 27,37 & 78,77 & 0,33 & 20,91 \\
Tachigali chrysophylla & 4195,14 & 28,53 & 78,59 & 3,12 & 18,29 \\
Inga edulis & 4160,50 & 28,35 & 79,78 & 0,63 & 19,59 \\
\hline
\end{tabular}

O poder calorífico representa a quantidade de calor liberado quando uma dada quantidade de combustível é queimada completamente. Dessa forma, a maior quantidade liberada de calor foi registrada para Acacia mangium $(4430,37 \mathrm{kcal} / \mathrm{kg})$, enquanto a menor foi para Inga edulis $(4160,50 \mathrm{kcal} / \mathrm{kg})$.

As três espécies alcançaram um valor médio de qualidade energética que satisfaz uma faixa de estudos, realizada por Brito (1993), onde o valor para folhosas tropicais está entre 3500 e $5000 \mathrm{kcal} / \mathrm{kg}$. Resultados semelhantes foram observados por Araújo (2000), quando encontrou um poder calorífico de $4088,50 \mathrm{kcal} / \mathrm{kg}$ para a espécie exótica Nim indiano (Azadirachta indica A. Juss), por Vale et al. (2001), com valor médio de $4641 \mathrm{kcal} / \mathrm{kg}$ para madeira de Eucalyptus grandis, e por Quirino et al. (2004), com $4798 \mathrm{kcal} / \mathrm{kg}$.

Observa-se, ainda, que o maior poder calorífico, por sua vez, está relacionado ao menor teor de cinza e maior de carbono fixo. Entretanto, quando comparados os valores de Tachigali chrysophylla e Inga edulis, eles não refletem a relação, mas podem estar associados à qualidade do solo, ou capacidade de absorção de macro e micronutrientes. Da mesma forma, Vale et al. (2011) afirmam que o teor de cinza está relacionado com a presença de minerais provenientes, em parte, da adubação química, como cálcio, potássio, fósforo, magnésio, ferro e sódio, entre outros.

A maior porcentagem de cinzas foi encontrada para Tachigali chrysophylla $(3,12 \%)$, quando comparada com Acacia mangium (0,33\%) e Inga edulis (0,63\%), que obtiveram os menores valores. Da mesma forma, Marabotto et al. (1991) observaram a variação no teor de cinzas num estudo com 28 espécies da Amazônia Peruano-Brasileira, a Aniba puchury-minor (Mart.) Mez (0,11\%), Osteophloeum plastyspermum (Spruce ex A.DC.) Warb. (0,28\%), Humiria balsamifera (Aubl.) A. St.-Hil. (0,58\%), 
Sapium marmieri Huber (0,76\%), Virola albidiflora Ducke (1,04\%), Apuleia leiocarpa (Vogel) J.F. Macbr. (1,14\%), Bombax munguba Mart. \& Zucc. (2,32\%) e Maquira coreacea Mart. \& Zucc. $(4,91 \%)$.

Para Vale et al. (2007), o teor de cinza está relacionado com a presença de quantidades e de qualidades diferentes de minerais presentes na biomassa. A lenha é um combustível muito utilizado em caldeiras e tem teor de cinzas em torno de $1 \%$, o que é bom índice para não prejudicar caldeiras e fornalhas.

O teor de umidade é uma propriedade que varia na madeira e na casca de modo bastante amplo, e é a propriedade que traz muita influência nos processos de combustão, pois apresenta uma relação inversa com o poder calorífico (VALE et al., 2011). A espécie Acacia mangium (27,37\%) obteve o menor teor de umidade na base seca, enquanto as espécies Tachigali chrysophylla $(28,53 \%)$ e Inga edulis $(28,35 \%)$ alcançaram valores de umidade semelhantes. Entretanto, foi observado que Acacia mangium e Tachigali chrysophylla perderam a mesma porcentagem de umidade, a saber, 7,89\%, e quando comparadas a Inga edulis $(8,07 \%)$, elas perderam mais umidade para igual período de tempo. Essa característica é importante, pois a escolha da madeira que possua perda de umidade rápida é essencial no processo produtivo, e essa característica foi observada nas espécies estudadas, com destaque para Acacia mangium e Tachigali chrysophylla.

A espécie Inga edulis $(79,78 \%$ e 19,59\%) obteve maior porcentagem de materiais voláteis e menor de carbono fixo, respectivamente, em contraste a Acacia mangium (78,77\% e $20,91 \%)$. A proporção entre esses componentes influencia as características de queima do combustível, pelo fato de os materiais voláteis, quando aquecidos, saírem do material e se queimarem rapidamente na forma gasosa, enquanto o carbono fixo queima-se vagarosamente na fase sólida. Nesse sentido, Vale et al. (2011) afirmam que combustíveis com alto índice de carbono fixo apresentam queima mais lenta, implicando maior tempo de residência nos aparelhos de queima, em comparação com outros que tenham menor teor de carbono fixo.

Já Brito e Barrichelo (1978) encontraram o menor teor de matérias voláteis na madeira de Byrsonima verbascifolia (L.) Rich. (74,62\%), e o maior teor para Tabebuia ochracea (Cham.) Standl. $(81,20 \%)$, enquanto a Lafoensia pacari St.-Hil. $(24,75 \%)$ destacou-se com o maior valor de carbono fixo na madeira.

Observou-se que os dados médios encontrados para carbono fixo e materiais voláteis estão adequados à faixa de valores citada por Brito e Barrichelo (1978), quando determinaram a variação de carbono fixo entre 15 e $25 \%$, e de materiais voláteis de 75 a $85 \%$.

Observou-se, nos dados médios, que o maior valor de carbono fixo (Acacia mangium) está relacionado ao maior poder calorífico e menor teor de cinzas e umidade. Entretanto, os valores de carbono fixo nas demais espécies não estão relacionados aos materiais voláteis e cinzas. Quanto à correlação dessas características, Vale et al. (2007) afirmam que o teor de carbono fixo está indiretamente relacionado com os teores de material volátil e cinzas. O poder calorífico superior, por sua vez, está diretamente relacionado com o teor de carbono fixo.

\section{CONCLUSÕES}

- As espécies apresentaram bom desempenho em altura e diâmetro e adaptabilidade ao solo da região.

- A densidade básica da madeira das espécies variou entre $0,39 \mathrm{~g} / \mathrm{cm}^{3}$ a $0,66 \mathrm{~g} / \mathrm{cm}^{3}$, o que as inclui entre as madeiras de densidade baixa, média e levemente densa.

- O maior valor médio de poder calorífico foi observado na Acacia mangium (4430,37 kcal $/ \mathrm{kg})$.

- Com base nos valores encontrados para análise imediata, caracterizam-se as espécies como produtoras de lenha de boa qualidade.

- O resultado apresentado vislumbra a utilização dessas espécies em um programa de plantio comercial com o objetivo de produzir biomassa para obtenção de lenha.

\section{REFERÊNCIAS}

ARAÚJO, L. V. C.; RODRIGUEZ, L. C. E.; PAES, J. B. Características físico-químicas e energéticas da madeira de Nim indiano. Scientia Forestalis, n. 57, p. 153 - 159, 2000.

AROLA, R. A. Wood fuels - How do they stack up? Forest Products Research Society, November 1517, Atlanta, Georgia, 1976, 12 p. 
ASSOCIAÇÃO BRASILEIRA DE NORMAS TÉCNICAS (ABNT). NBR 8112:1986 Carvão vegetal Análise imediata. Rio de Janeiro: ABNT, 1986. 5 p. 1984. $13 \mathrm{p}$.

NBR 8633:1984 Carvão vegetal - Determinação do poder calorífico. Rio de Janeiro: ABNT, NBR 11941:2003 Madeira - Determinação da densidade básica. Rio de Janeiro: ABNT, 2003. $6 \mathrm{p}$.

BAGGIO, A. J.; CARPANEZZI, A. A.; SANMIGUEL, A. A. Equações para a estimativa de peso da biomassa aérea de bracatinga (Mimosa scabrella Benth.) na idade de corte. Embrapa Florestas. Boletim de Pesquisa Florestal, Colombo, n. 30-31, p. 37 - 49, 1995.

BRASIL. Ministério da Agricultura Secretaria Nacional de Planejamento Agrícola. Aptidão agrícola das terras do Amazonas. Estudos básicos para o planejamento agrícola, aptidão agrícola das terras. 121. Brasília, 1979. $142 \mathrm{p}$.

BRASIL, M. A. M.; FERREIRA, M. Variação da densidade básica da madeira de Eucalyptus alba Reinw, Eucalyptus saligna Smith e Eucalyptus grandis Hill ex-Maiden aos 5 anos de idade, em função do local e do espaçamento. IPEF, v. 2, n. 3, p. 129 - 149, 1971.

BRITO, J. O. Uso direto da biomassa florestal: processos tradicionais. In: ABREU, Y. V.; OLIVEIRA, M. A. G.; GUERRA, S. M. G. Energia sociedade e meio ambiente. Malaga, Espanha: Eumed. Net, Universidad de Malaga, 2010. p. 86.

Expressão da produção florestal em unidades energéticas. In: VI Congresso Florestal Brasileiro, 6., Pan Americano, 1., Curitiba, Anais do... Curitiba: SBS, 1993. p. 280 - 282.

CORDER, S. E. Fuel characteristics of wood and bark and factors affecting heat recovery. Proceedings of the Conference on Wood Residue as an Energy Source. Madison, Wisconsin. N: p. 75. Forest Products Research Society. 1976.

COUTO, H. T. Z.; BATISTA, J. L. F.; RODRIGUES, L. C. E. Mensuração e gerenciamento de pequenas florestas. Documentos Florestais. Piracicaba, n. 5, p. 1 - 37, 1989.

INGHAM, J. M. Biomassa no mundo e no Brasil. In: Fontes não convencionais de energia: as tecnologias solar, eólica e de biomassa. Organização e edição: Alexandre de A. Montenegro, 2. ed. Florianópolis: Editora da UFSC, 1999. 160 p.

JUNGE, D. C. Boilers fired with wood and bark residues. Forest Research Laboratory Research Bulletin 17. Corvallis, Oregon. 57 p. 1975.

LIMA, P. C. F. Algaroba: uma das alternativas para o Nordeste. Brasil florestal, n. 58, p. 47 - 54, 1984.

MARABOTTO, M. T.; MOENA, A. C.; CUNHA, M. P. S. C. Alternativas energeticas de veintiocho especies forestales de la Amazonia Peruano-Brasileña. Série Técnica, n. 02. Lima, Peru, 1991. 46 p.

OLIVEIRA, B. Produção de carvão vegetal: aspectos técnicos. In: Produção e utilização de carvão vegetal. CETEC, MG. p. 61 - 73, 1982.

QUIRINO, W. F.; VALE, A. T.; ANDRADE, A. P. A.; ABREU, V. L. S.; AZEVEDO, A. C. S. Poder calorífico da madeira e de resíduos lignocelulósicos. Biomassa \& Energia, v. 1, n. 2, p. 173 - 182, 2004.

REZENDE, M. A.; SAGLIETTI, J. R. C.; CHAVES, R. Variação da massa específica da madeira de Eucalyptus grandis aos 8 anos de idade em função de diferentes níveis de produtividade. Scientia Forestalis, n. 53. p. 71 - 78. 1998.

RIBEIRO, M. N. G. Os aspectos climatológicos de Manaus. Acta Amazônica, 6(2), p. 229 - 233. 1976.

SCHUMACHER, M. V. Aspectos ambientais das plantações de Pinus e Eucalyptus. Revista da Madeira, ano 13, n. 77, p. 92 - 94, 2003.

TRUGILHO, P. F.; LIMA, J. T.; MORI, F. A.; LINO, A. L. Avaliação de clones de Eucalyptus para 
produção de carvão vegetal. Cerne, Lavras-MG, v. 7, n. 2, p. 104 - 114, 2001.

VALE, A. T.; MENDES, R. M.; AMORIM, M. R. S.; DANTAS, V. F. S. Potencial energético da biomassa e carvão vegetal do epicarpo e da torta do pinhão-manso (Jatropha curcas). Cerne, Lavras, v. 17, n. 2 , p. $267-273,2011$.

VALE, A. T.; GENTIL, L. V.; GONÇALEZ, J. C.; COSTA, A. F. Caracterização energética e rendimento da carbonização de resíduos de grãos de café (Coffea arabica L.) e da madeira (Cedrelinga catenaeformis Duke.). Cerne, v. 13, n. 4, p. 416 - 420, 2007.

VALE, A. T.; MOURÃ, M. A.; LEÃOS, B. A. Quantificação e caracterização energética da madeira e casca de espécies do cerrado. Ciência Florestal, v. 12, n. 1, 2002.

VALE, A. T.; FIEDLER, N. C.; SILVA, G. F. Avaliação energética da biomassa do cerrado em função do diâmetro das árvores. Ciência Florestal, Santa Maria, v. 12, n. 2, p. 115 - 126. 2001.

VALE, A. T.; BRASIL, M. A. M.; LEÃO, A. L. Caracterização da madeira e da casca de Sclerolobium paniculata, Dalbergia miscolobium e Pterodon pubescens para uso energético. In: Agrener 2000: 3 Encontro de Energia no Meio Rural, 2000. Campinas. Anais... Campinas: NIPE/CAMPINAS, 2000. v. 01. p. $18-19$.

VITAL, B. R. Métodos de determinação da densidade da madeira. Boletim Técnico, 2. Viçosa: SIF, 1984. $21 \mathrm{p}$. 